\title{
Obituary Peter B Dews
}

Neuropsychopharmacology (2013) 38, 2733; doi: $10.1038 / n p p .2013 .276$

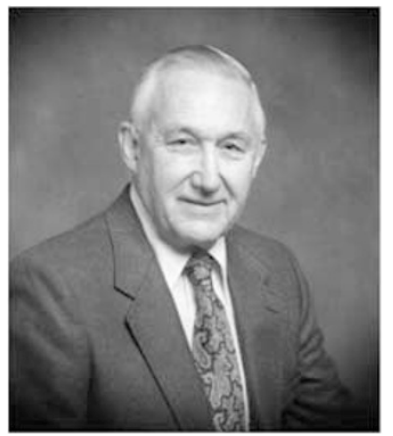

Peter B Dews (1922-2012) passed away on 2 November in the Brigham and Women's Hospital a few steps from Harvard Medical School where he spent the majority of his career and where his intellectual and research efforts shaped the way in which the behavioral effects of drugs are studied. That short physical distance contrasts with the expanse of Dews' academic journey and his vast influence on the discipline of behavioral pharmacology. His experiments and writings touched on broad issues, but his most penetrating insights came in the study of behaviorally active drugs. Considered appropriately to be the principal founder of behavioral pharmacology, Dews is widely recognized as the single individual most responsible for the development of the discipline. He combined a rigorous assessment of the behavioral effects of drugs with a corresponding emphasis on principles of behavior analysis. He became a powerful advocate for understanding behavior as a dynamic expression of biology and of the need for biological scientists to have an understanding of behavior in objective and quantifiable terms.

Peter Dews was born in the north of England, in Yorkshire, and received his medical degree from the University of Leeds in 1944 working under WH Bain. He left the Department of Pharmacology at Leeds to work with $\mathrm{JH}$ Burn at Oxford University and then went to Edinburgh where, with Sir Henry Gaddum, he studied the pharmacological effects of the antihistamine pyrilamine. In 1948 he moved to the United States under a research fellowship at Burroughs Wellcome in Tuckahoe, New York, where he conducted his first published study on the behavioral effects of drugs, using locomotor activity that he termed 'voluntary behavior'. He subsequently accepted a Fellowship at the Mayo Foundation in the laboratory of Charles Code, and earned a PhD in Physiology (1951) from the University of Minnesota.

When Professor Otto Krayer, Chair of Pharmacology at Harvard Medical School, gave a Mayo Foundation Lecture in 1952, he recruited Dews for a position as Instructor. When Dews arrived at Harvard in 1953, Krayer suggested that he call on BF Skinner in the Department of Psychology. Skinner had been promoting behavioral techniques to Krayer that he thought would be useful for pharmacologists interested in the behavioral effects of drugs. Dews met with Skinner and then with CB Ferster who provided a tour of the laboratory. This was a pivotal moment in directing Dews' research interests. Dews was impressed by the studies in Skinner's laboratory; the manner in which behavioral responses of pigeons were recorded cumulatively in real time resembled the kymograph recordings that were of enormous value to physiology and pharmacology. In a retrospective, Dews commented that it was immediately apparent from the counters and cumulative records that behavioral phenomena were being studied in a way that was well suited for application to pharmacology'. Dews incorporated those techniques into his first studies with drugs and thereafter was committed to an experimental analysis of behavior and to the detailed analysis of the behavioral effects of drugs. Dews' publication, 'Studies on Behavior', and subsequent articles represent significant landmarks that established the foundation as well as the guideposts for the emergence and growth of behavioral pharmacology. The influence of the schedule of reinforcement in determining the effects of pentobarbital was striking and led to a recurring emphasis on the importance of examining behavioral consequences in studying the behavioral effects of drugs.

Dews had an exceptional sense for language and he addressed complex issues with a clarity of thought and expression. Dews viewed schedules as central principles that governed behavior and considered them to be as fundamental to behavior as osmosis is to physiology and evolution is to the selection and propagation of species. The emphasis on schedules of reinforcement weaves together many threads in the fabric of his work. The disciplines of both behavioral pharmacology and the experimental analysis of behavior are enduring testimonies to his spirited and profound contributions.

Dews was appointed Stanley Cobb Professor of Psychiatry and Psychobiology in 1962. He was elected to the American Academy of Arts and Science and the Institute of Medicine. He served for 15 years as the director of educational activities for the International Brain Research Organization and was a founding member of ACNP.

Peter B Dews is survived by his wife Grace; daughter Pamela Rentschler; sons, Kenneth, Alan, and Michael; a sister, Jean Hilditch, in England; nine grandchildren, and a great-grandchild.

\footnotetext{
James E Barrett ${ }^{1}$, Jack Bergman ${ }^{2}$, Jonathan $\mathrm{L} \mathrm{Katz}^{3}$ and $\mathrm{W} \mathrm{H}$ Morse ${ }^{2}$ ${ }^{1}$ Drexel University College of Medicine, Philadelphia, PA, USA; ${ }^{2}$ Harvard Medical School, Boston, MA, USA;

${ }^{3}$ National Institute on Drug Abuse, Baltimore, MD, USA E-mail: james.barrett@drexelmed.edu
} 